\title{
Orthorexia nervosa and its association with alexithymia, emotion dysregulation and disordered eating attitudes among Lebanese adults
}

\author{
Sahar Obeid ${ }^{1,2} \cdot$ Souheil Hallit ${ }^{2,3}$ (D) Marwan Akel $^{2,4} \cdot$ Anna Brytek-Matera $^{5}$ \\ Received: 16 November 2020 / Accepted: 13 January 2021 / Published online: 11 February 2021 \\ (c) The Author(s), under exclusive licence to Springer Nature Switzerland AG part of Springer Nature 2021
}

\begin{abstract}
Objective This study aims to explore whether orthorexia nervosa, like other eating disorders, is associated with difficulties identifying, describing, and regulating one's own emotions among a sample of Lebanese adults.

Methods A cross-sectional study was conducted during October 2020, during the lockdown period imposed by the government for the COVID-19 pandemic. All participants above 18 years of age were allowed to participate in this study. A total of 787 Lebanese adults out of 920 (85.54\%) completed an online survey including Arabic versions of the ORTO-R measure of orthorexia, the Toronto Alexithymia Scale, the Difficulty in Emotion Regulation Scale, and the Eating Attitudes Test.

Results After making sure that all norms are verified, hierarchical linear regressions were conducted to evaluate the association between disordered eating attitudes (EAT scores) and ON (model 1), and after controlling for difficulties in emotion regulation (DERS score) (model 2). Model 1 accounted for $15.1 \%$ of the variance of ON (adj. $R^{2}=0.151, F(1,786)=140.06$, $p<0.001)$ and showed that higher levels of disordered eating (higher EAT scores) $(\beta=0.15)$ were significantly associated with more ON tendencies and behaviors. When adding the DERS total score to the model, Model 2 was a much better fit with $17.7 \%$ of the variance of ON (adj. $\mathrm{R}^{2}=0.177, F(2,786)=84.44, p<0.001$ ), with higher levels of emotion dysregulation (higher DERS scores) $(\beta=0.06)$ and more disordered eating attitudes (higher EAT scores) $(\beta=0.13)$ were associated with higher levels of ON (Table 5).
\end{abstract}

Conclusion The present research suggests that people with high $\mathrm{ON}$ tendencies experience troubles recognizing, regulating, and describing their emotions, similarly to other disordered eating.

Level of evidence 5 .

Keywords Orthorexia nervosa $\cdot$ Alexithymia $\cdot$ Emotional difficulties $\cdot$ Emotional dysregulation

Sahar Obeid and Souheil Hallit are first co-authors.

Sahar Obeid

saharobeid23@hotmail.com

$\triangle$ Souheil Hallit

souheilhallit@hotmail.com

1 Faculty of Arts and Sciences, Holy Spirit University of Kaslik (USEK), Jounieh, Lebanon

2 INSPECT-LB, Institut National de Santé Publique, Épidémiologie Clinique et Toxicologie-Liban, Beirut, Lebanon

3 Faculty of Medicine and Medical Sciences, Holy Spirit University of Kaslik (USEK), Jounieh, Lebanon

4 School of Pharmacy, Lebanese International University, Beirut, Lebanon

5 Institute of Psychology, University of Wroclaw, Wroclaw, Poland

\section{Background}

Healthy eating is an important measure of a healthy way of living and is linked with multiple advantages such as decreased risk of diabetes, obesity, cancer and heart disease [1]. Though, for some individuals, the concern for following a healthy diet becomes physically and socially impairing. Orthorexia nervosa $(\mathrm{ON})$ is defined as an irrational obsession with healthy/clean eating [2]. The ultimate goal in $\mathrm{ON}$ is to get a feeling of purity or well-being and not to lose weight [3]. With time, people with ON spend more and more time buying, scheduling, and making healthy meals, which ultimately turns into an obsession interfering with different areas of life [4]. More particularly, individuals with ON frequently escape situations that consist of going out to eat with others, and might suffer from physical problems, such as malnutrition and 
excessive weight loss [5]. To date, neither in the DSM-5 [6] nor in the ICD-11 [7] is ON officially recognized as a separate eating disorder, a variant of eating or obsessive compulsive disorder or as a disturbed eating habit [3] in both DSM-5 [6] or ICD-11 [7].

Within the framework of the studies carried out on the prevalence of ON, several questionnaires [8] were used, but the most recognized is the ORTO-15 [9]. However, the measurement quality of ORTO-15 is repeatedly criticized for its psychometric, leading to diverse results across multiple populations [10]. In light of the problems related with the measurement of ON by ORTO-15, a revised version of it (ORTO-R) was developed for the purpose of measuring/screening for orthorexic thoughts and behaviors [11]. Thus, ORTO-R does not assess the prevalence of ON and makes the administration of the measure more appealing and intuitive [11]. Since ORTO-R has been developed recently, no psychometric validation of the scale was performed in Lebanon.

Multiple models have been suggested concerning the association of emotions with disordered eating; in fact, subjects with disordered eating behaviors exercise excessively to avoid/cope with their emotions [12, 13]. More particularly, subjects with disordered eating demonstrate difficulties regulating their feelings [14] as well as identifying and describing them [15]. First of all, emotion regulation (ER) skills are necessary to efficiently cope with undesirable emotions. ER is a complex theoretical model that involves four dimensions of ER with different behavioral and cognitive features: [16] (1) goal-directed behavior and impulse control; (2) awareness and understanding of emotions; (3) acceptance of emotional responses; and (4) availability of ER strategies perceived as effective. It is well known that subjects with eating disorders (ED) have considerable difficulty regulating their emotions [14]. Other studies also reported alteration of these dimensions in adults with ED compared to healthy controls $[17,18]$. As for orthorexia nervosa, a recent study [19] showed that ER difficulties were correlated with ON tendencies, in line with previous studies conducted on other eating disorders [14]. To be noted that the deregulation of emotions contributes to the development and maintenance of ED [14].

As for alexithymia, this concept includes difficulties recognizing and expressing feelings, discriminating between emotions and physical sensations, and an actual intellectual style focused on the external milieu [20]. The Toronto Alexithymia Scale (TAS-20) is the most common tool used to measure alexithymia under three aspects: difficulty identifying feelings (DIF); difficulty describing feelings (DDF) and externally oriented thinking (EOT) [21]. Individuals with EDs usually show high DDF and DIF, but not EOT, scores [22]. A recent study showed that only the DIF subscale, and not the total TAS score, was considerably linked with ON symptoms [19].

Numerous sociodemographic characteristics have been associated with orthorexic tendencies [23]. The association between gender and ON remains controversial, with contradictory results; different studies revealed that $\mathrm{ON}$ symptomatology was significantly greater in women than men [24], greater in men than women [5, 25] or did not show any association [26]. The same controversy applies to the association between $\mathrm{ON}$ and socioeconomic status [10, 27, 28]. As for age, the results are inconsistent as well, showing weak or no association [29]. Regarding marital status, the results fluctuate between a significant $[5,30]$ or lack of correlation [31] between marital status and ON. Regarding Body Mass Index (BMI), part of being physically healthy is preserving a fitting body weight; studies have found that higher ON symptomatology links to greater BMI [31].

Based on previous research, results showed that $20.8 \%$ of the Lebanese population were alexithymic [32] and $75.2 \%$ had orthorexic behaviors (according to the ORTO-15 scale) [33]. Therefore, the objective of the present study, the first of its kind in the country as far as we know, to assess the association between orthorexia nervosa and difficulties identifying, describing and regulating one's own emotions among a sample of Lebanese adults. We hypothesize that, based on previous work, that alexithymia and emotion regulation difficulties would be correlated with higher ON. Since disordered eating attitudes have been found to be related to more ON tendencies [29], we controlled for this variable in our analysis.

\section{Methods}

\section{General study design}

A cross-sectional study was carried out in October 2020, during the lockdown period imposed by the government for the COVID-19 pandemic using a sample of communitydwelling participants. Due to the restrictions on gatherings and the non-practical and risky side of face-to-face interviews, we created the survey on Google forms as a link (https://docs.google.com/forms/d/14kaK46L3jRuHiZ 6 ptPS00wGlnuhkjfKEZMadWLgcXNo/edit). The link was shared among the participants and sent to all governorates of Lebanon (Beirut, Mount Lebanon, North, South, and Bekaa) using the snowball technique. Participants were asked to fill the survey online and send the link to other friends or family members too, which explains the snowball sampling technique used. All participants above 18 years of age were allowed to participate in this study. 


\section{Minimal sample size calculation}

According to the G-power software, and based on an effect size f $2=2 \%$, an alpha error of $5 \%$, a power of $80 \%$, and controlling for 12 factors in the multivariable analysis, a minimal number of 395 was needed. The response rate was $85.54 \%$; a total of 787 participants out of 920 was enrolled at the end of the data collection.

\section{Questionnaire and variables}

The Arabic self-administered questionnaire with closedended questions was anonymous; the questionnaire required approximately $25 \mathrm{~min}$ to be completed. The questionnaire consisted of different sections. The first part clarified sociodemographic characteristics: age, gender, marital status, educational level, and household crowding index. The latter, reflecting the socioeconomic status of the family, was calculated by dividing the number of persons in the house by the number of rooms in the house excluding the bathrooms and kitchen. The physical activity index was calculated by multiplying the intensity by the frequency by the time of physical activity [34]. The second part of the questionnaire included the following scales:

\section{ORTO-R}

This six-item scale [11] is a revised version of the ORTO-15 scale [35], validated in Lebanon [36, 37]. Items were scored from $0=$ never to $3=$ always. Higher scores indicate more orthorexia nervosa tendencies and behaviors. The Cronbach's alpha of this scale in this study was 0.785 .

\section{Toronto Alexithymia Scale (TAS-20)}

The Arabic version of the scale was used with the permission of Pr. Graham Taylor. This scale is composed of 20 items [38]. Its good reliability was confirmed in our study for the total score $(\alpha=0.897)$ and the three subscales: difficulties identifying feelings (DIF) $(\alpha=0.868)$, difficulties describing feelings (DDF) $(\alpha=0.613)$ and externally oriented thinking (EOT) $(\alpha=0.825)$.

\section{Difficulty in Emotion Regulation Scale (DERS-16)}

It is a 16-item scale that assesses emotion regulation [39]. Items are graded using a 5-point Likert scale. Higher scores reflect more emotion regulation difficulties. Within the scale are five subscales: clarity ( 2 items), goals (3 items), impulse
(3 items), non-acceptance (3 items) and strategies (5 items). This scale has good reliability [40], which was confirmed in our sample (total: $\alpha=0.932$, clarity: $\alpha=0.828$; goals: $\alpha=0.825$; impulse: $\alpha=0.839$; non-acceptance: $\alpha=0.732$; strategies: $\alpha=0.849$ ).

\section{Eating Attitude Test (EAT-26)}

The EAT-26 measures attitudes and behaviours related to disordered eating. This scale, validated in Lebanon [41], comprises 26 items [42], scored as follows: $0=$ infrequently/ almost never/never to $3=$ always. Scores $\geq 20$ indicate disordered eating attitudes [42]. In this study, the scale's reliability was excellent $(\alpha=0.901)$.

\section{Translation procedure}

The DERS scale was forward and back-translated. Forward translation (English to Arabic) was performed by one translator, whereas the back translation from Arabic to English was performed by a second translator. Minor discrepancies were solved by consensus.

\section{Statistical analysis}

The Statistical Package for Social Sciences 25.0 (SPSS, Chicago, IL, USA) was used for the data analysis. Another sample, totally different from the one recruited for the current study was used to conduct an exploratory and confirmatory factor analysis $(N=300)$. An exploratory factor analysis (EFA) was run using the principal component analysis technique. Since the extracted factors were found to be significantly correlated, the promax rotation technique was used. To ensure the model's adequacy, the Kaiser-Meyer-Olkin (KMO) measure of sampling adequacy and Bartlett's test of sphericity were calculated. Factors with an Eigen value higher than one were retained. Moreover, Cronbach's alpha values were recorded for reliability analysis for the total scale and its subscales.

There was no missing data in the database collected for this current study (from the 787 participants independent from the other 811 participants) since all questions required an answer in the link. Since the ORTO-R score was not normally distributed (verified by the Shapiro-Wilk test), nonparametric tests were used; this included the Mann-Whitney and Kruskal-Wallis tests to compare two and three or more means, respectively, whereas the Spearman correlation test was used to compare two continuous variables. A hierarchical linear regression was conducted to check for correlates associated with orthorexia nervosa tendencies; in the first step, sociodemographic variables were entered; in the second step, we entered the TAS-20 and DERS- 16 total scores; in the third step, we entered the EAT-26 total score to 
determine if emotions difficulties are characteristics of $\mathrm{ON}$, or are due to shared inferences with eating psychopathologies. Coefficient values of $|0.1-0.23|,|0.24-0.36|$, and $>|0.37|$ indicated small, moderate, and large correlations, respectively. All studied variables that showed a correlation coefficient $r>|0.24|$ were entered as independent variables in the regression analysis [43]. Significance was set at $p<0.05$.

\section{Results}

\section{Sample 1}

\section{Sociodemographic and other characteristics}

The mean age of the participants was $23.87 \pm 8.75$ years, with most females $(77.7 \%)$.

\section{Exploratory factor analysis of the ORTO-R scales items}

All items of the ORTO-R were extracted and yielded a two-factor solution with Eigenvalues $>1$ (variance explained $=68.21 \% ; \mathrm{KMO}=0.718$; Bartlett's sphericity test $p<0.001 ; \alpha$ Cronbach $=0.755)($ Table 1$)$.

Table 1 Factor analysis of the ORTO-R scale items using the varimax rotation among Lebanese sample

\begin{tabular}{llc}
\hline Variable & $\begin{array}{l}\text { Item number } \\
\text { from ORTO-15 }\end{array}$ & Factor 1 Factor 2 \\
\hline Does eating healthy food change your lifestyle (frequency of eating out, friends, etc.)? & 11 & 0.896 \\
Do you believe that strict consuming only of healthy food may improve your appearance? & 12 & 0.821 \\
Would you agree that eating healthy food increases your self-esteem? & 10 & 0.770 \\
In the last three months, did thoughts of food make you feel guilt, ashamed and anxious? & 3 & 7 \\
Does thinking about food excessively worry you for more than three hours a day? & 4 & 0.831 \\
Are your rigid and restrictive dietary choices conditioned by your worry about your health status? & 0.824 \\
Percentage of variance explained & 0.751 & 22.59 \\
Cronbach's alpha & 0.722 \\
\hline
\end{tabular}

Table 2 Sociodemographic characteristics of the participants $(N=787)$

\begin{tabular}{lr}
\hline Variable & $N(\%)$ \\
\hline Gender & $255(32.4 \%)$ \\
Males & $532(67.6 \%)$ \\
Females & \\
Marital status & $618(78.5 \%)$ \\
Single/widowed/divorced & $169(21.5 \%)$ \\
Married & $50(6.4 \%)$ \\
Education level & $125(15.9 \%)$ \\
Complementary or less & $612(77.8 \%)$ \\
Secondary & Mean \pm SD \\
University & $26.33 \pm 12.16$ \\
\hline & $29.20 \pm 21.23$ \\
\hline Age (in years) & $1.08 \pm 0.51$ \\
Physical activity index & $24.06 \pm 4.72$ \\
Household crowding index & \\
Body Mass Index $\left(\mathrm{kg} / \mathrm{m}^{2}\right)$ & \\
\hline
\end{tabular}




\section{Sample 2}

\section{Sociodemographic and other characteristics}

The mean age of the participants was $26.33 \pm 12.16$ years, with most females $(67.6 \%)$. Other characteristics are summarized in Table 2.

\section{Bivariate analysis}

Higher EAT scores (more disordered eating attitudes), higher TAS scores (higher levels of alexithymia) higher DERS scores (higher levels of emotion regulation difficulties), higher physical activity and higher BMI were significantly associated with higher ORTO-R scores (more ON tendencies and behaviors). It is noteworthy that age, gender, household crowding index, marital status and education level were not significantly associated with ORTO-R scores (Tables 3 and 4).

\section{Multivariable analysis}

After making sure that all norms are verified, hierarchical linear regressions were conducted to evaluate the association between disordered eating attitudes (EAT scores) and ON (model 1), and after controlling for difficulties in emotion regulation (DERS score) (model 2). Model 1 accounted for $15.1 \%$ of the variance of ON (adj. $R^{2}=0.151$, $F(1,786)=140.06, p<0.001)$ and showed that higher

Table 3 Bivariate analysis of categorical variables associated with the ORTO-R scores

\begin{tabular}{ll}
\hline Variable & ORTO-R \\
\hline Gender & \\
Males & $7.51 \pm 4.70$ \\
Females & $8.07 \pm 4.25$ \\
$p$ & 0.135 \\
Effect size Cohen $d$ & 0.124 \\
Marital status & \\
Single/widowed/divorced & $7.85 \pm 4.24$ \\
Married & $8.05 \pm 4.96$ \\
$p$ & 0.741 \\
Effect size Cohen d & 0.171 \\
Education level & \\
Complementary or less & $7.68 \pm 4.96$ \\
Secondary & $7.10 \pm 4.34$ \\
University & $8.07 \pm 4.36$ \\
$p$ & 0.116 \\
Effect size Cohen $d$ & 0.167 \\
\hline
\end{tabular}

Inferential statistics: $U$ gender for the Mann-Whitney test $=63,377.5$ and for marital status $=51,356.5 ; H$ value of the Kruskal-Wallis test for the education level $=4.3$ levels of disordered eating (higher EAT scores) $(\beta=0.15)$ were significantly associated with more $\mathrm{ON}$ tendencies and behaviors. When adding the DERS total score to the model, Model 2 was a much better fit with $17.7 \%$ of the variance of ON (adj. $\left.R^{2}=0.177, F(2,786)=84.44, p<0.001\right)$, with higher levels of emotion dysregulation (higher DERS scores) $(\beta=0.06)$ and more disordered eating attitudes (higher EAT scores) $(\beta=0.13)$ were associated with higher levels of ON (Table 5).

Similar results were obtained when introducing the DERS subscales scores as independent variables (Table 6); Model 2 was a much better fit with $18.1 \%$ of the variance of ON (adj. $\left.R^{2}=0.181, F(3,786)=57.62, p<0.001\right)$, with higher DERS non-acceptance scores $(\beta=0.16)$, DERS strategies scores $(\beta=0.09)$, and more disordered eating attitudes (higher EAT scores) $(\beta=0.13)$ were associated with higher levels of ON (Table 6).

\section{Discussion}

Empirical data on defining feature related to $\mathrm{ON}$ are scarce and still are debated. Therefore, the present study explored the typology of Lebanese adults from a non-clinical sample based on ON, alexithymia, emotion dysregulation and disordered eating attitudes. In our study, higher levels of alexithymia, emotion regulation difficulties, physical activity, disordered eating attitudes and BMI were significantly associated with more ON.

As far as we know, one study [19] showed that ON was related to emotions identification and regulation difficulties. More precisely, ON was associated with problems committing to goal-directed conducts or impulse control difficulties when distressed, rejection of emotional reactions, and limited suitable emotion regulation strategies. In addition, ON was associated with difficulties in emotion identification (alexithymia) [19]; a recent study [44] found that alexithymia was positively associated with disordered and emotional eating, as well as eating in the absence of hunger in youth. In case of ON, subjects regularly limit their diet to "pure" and "clean" types of foods, a behavior that can intensify with time [45]. The unreasonable preoccupation with healthful food quality and the restrictive control over food consumption seen in such people might lead to a noteworthy disturbance to their functioning, which can damage their capability to participate in social activities/life, and consequently a loss of social relationships [45, 46]. In addition, diminished recognition/acknowledgment of others' feelings can inhibit the flexibility, connections and preservation of relationships, by making it hard for subjects to reply suitably to the expressions of feeling of other people [47].

ON behaviors may be used as a coping strategy by subjects who have poor emotion regulation capabilities in order 


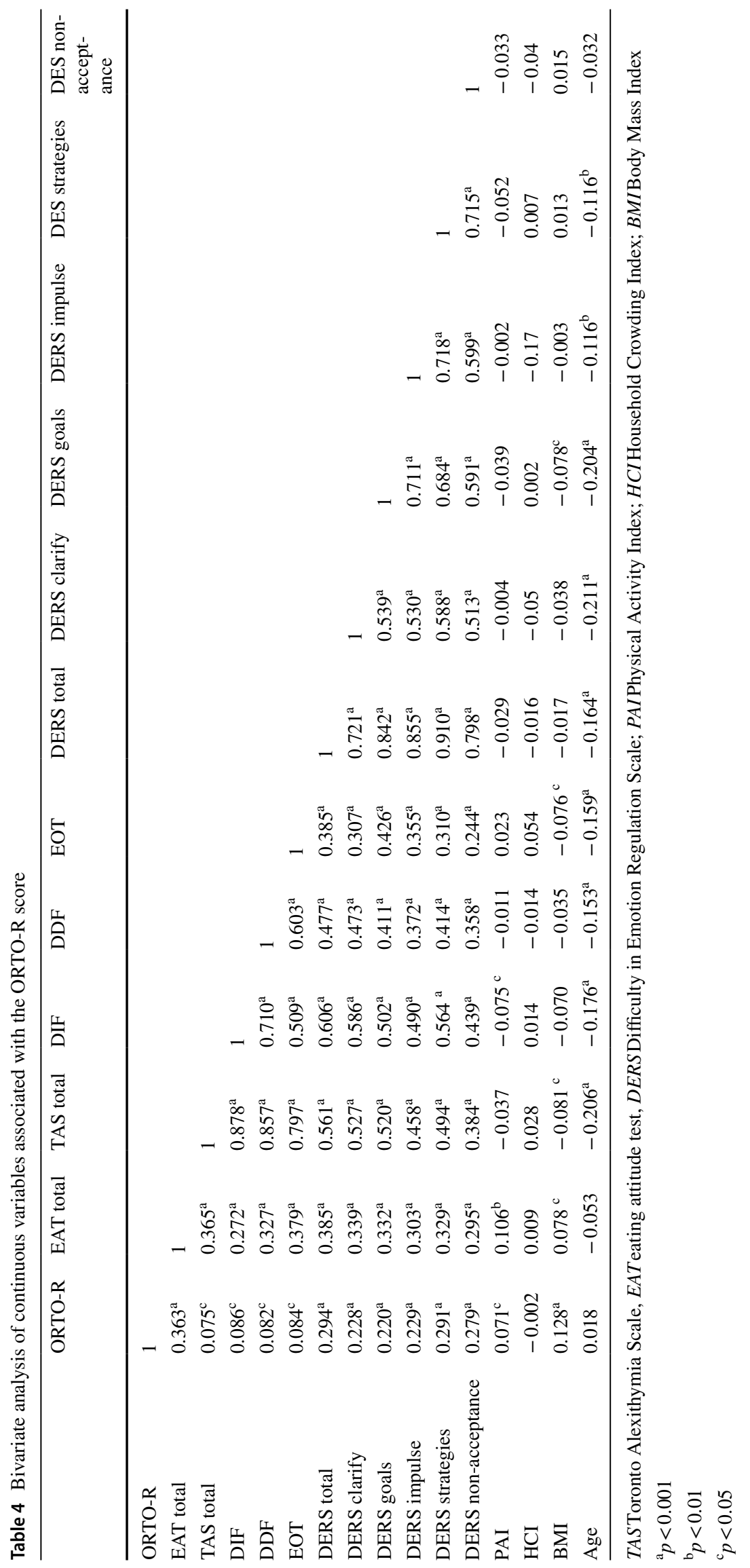


Table 5 Multivariable analysis: hierarchical linear regression taking the ORTO-R score as the dependent variable

\begin{tabular}{|c|c|c|c|c|}
\hline Variable & UB & SB & $p$ & $95 \% \mathrm{CI}$ \\
\hline \multicolumn{5}{|c|}{ Model 1 taking the EAT score as an independent variable } \\
\hline EAT total score & 0.15 & 0.39 & $<0.001$ & $0.13-0$. \\
\hline \multicolumn{5}{|c|}{$\begin{array}{l}\text { Model } 2 \text { taking DERS-16 and EAT total scores as independent } \\
\text { variables }\end{array}$} \\
\hline DERS total score & 0.06 & 0.17 & $<0.001$ & $0.03-0.08$ \\
\hline EAT total score & 0.13 & 0.33 & $<0.001$ & $0.10-0.1$ \\
\hline
\end{tabular}

Nagelkerke $R^{2}$ values: Model $1=15.1 \%$; Model $2=17.7 \%$; numbers in bold indicate significant $p$ values

$U B$ unstandardized beta, $S B$ standardized beta, $C I$ confidence interval, EAT eating attitude test, DERS difficulty in Emotion Regulation Scale

Table 6 Multivariable analysis: hierarchical linear regression taking the ORTO-R score as the dependent variable

\begin{tabular}{lcccr}
\hline Variable & UB & SB & $p$ & $95 \%$ CI \\
\hline Model 1 taking the EAT score as an independent variable \\
EAT total score & 0.15 & 0.39 & $<0.001$ & $0.13-0.18$ \\
Model 2 taking DERS-16 and EAT total scores as independent \\
variables \\
EAT total score & 0.13 & 0.34 & $<0.001$ & $0.10-0.16$ \\
DERS non-acceptance & 0.16 & 0.10 & 0.032 & $0.01-0.30$ \\
DERS strategies & 0.09 & 0.10 & 0.041 & $0.004-0.17$ \\
\hline
\end{tabular}

Nagelkerke $R^{2}$ values: Model $1=15.1 \%$; Model $2=18.1 \%$; numbers in bold indicate significant $p$ values

$U B$ unstandardized beta, $S B$ standardized beta, $C I$ confidence interval, EAT eating attitude test, DERS difficulty in Emotion Regulation Scale

to feel in control [19]. Dietary rules increase levels of perceived control. Hence, it is conceivable that individuals with ON tendencies incline towards more impulsivity and being 'out of control' when distressed/facing negative feelings [19]. The use of an extreme obsessive eating practices can, therefore, help reach more perceived control to better cope with hard emotions. This may be predominantly the situation if the person does not acknowledge their emotional responses and considers the absence of other approaches to make him/her feel better [19]. A previous study [45] pointed to perceptions of control and guilt as probable explanation behind the stigma of ON.

The link between ON and regular physical activity has been previously described [30, 48-52]; some findings have shown that more recurrent training was linked to higher $\mathrm{ON}$ in women [48], while others have demonstrated that ON and more physical activity were found in men [50]. The latter association was also found in active fitness members, in females more than males [52]. A recent study [49] has showed that increased physical exercise appears to play a significant role in $\mathrm{ON}$; people with $\mathrm{ON}$ tend to have lengthier workout periods [49] compared to the general population [30] and in a more obsessive way. They might not experience the pleasure of exercising since the latter is considered a strategy for regulating their "needs" [49]. Physical activity can improve health and decrease the risk of developing numerous illnesses as well as have instant and long-term health benefits. However, similarly to other eating disorders (especially anorexia nervosa), workout might possibly be considered as an ON symptom, with similar underlying pathological mechanism as the unhealthy way of healthy eating [49].

Our results are in line with other studies showing that more $\mathrm{ON}$ is linked to higher levels of disordered eating attitudes among adults [53-55] as well as increased BMI $[4,5,31,56,57]$. This may suggest a difference between $\mathrm{ON}$ and anorexia nervosa, which is marked by an excessively low BMI [4].

It is noteworthy that age, gender, household crowding index, marital status and education level were not significantly associated with $\mathrm{ON}$ in our Lebanese sample. Our results are consistent with previous findings $[25,58]$ and may suggest no gender and age differences, which is in contrast to anorexia nervosa. It is worth pointing out that there are inconsistent findings on link between $\mathrm{ON}$ and age, gender, educational level and Body Mass Index (BMI), which can be elucidated by sociocultural differences/characteristics between countries and the different measurement tools used [59].

The results of the multivariable analysis have found that in model 2 higher levels of emotion dysregulation were associated with more ON tendencies and behaviors, whereas alexithymia did not show any significant association with ON. However, in model 3, higher levels of emotion dysregulation, lower levels of alexithymia, and more disordered eating attitudes predicted higher levels of ON. Based on our results showing association between $\mathrm{ON}$ and emotion description difficulties, we can suggest that alexithymia exhibited by individuals with $\mathrm{ON}$ may not be a feature of $\mathrm{ON}$ per se. The interpersonal deficits linked with alexithymia may be predominantly pertinent for susceptibility toward disordered and disinhibited eating behaviors [44]. Problems in the identification and description of one's own emotions highly co-occur with all eating disorders (EDs) subtypes and with non-clinical ED symptomology [47]. Knowingly, reduced emotion recognition and higher alexithymia have beforehand been described in patients with ED, raising the likelihood that alexithymia, not ED symptomology, is accountable for the difficulties in the recognition of emotions [47]. The same explanation could also be assumed in case of ON. Our results were in opposite to those of Vuillier et al., who showed that emotion dysregulation was not a predictor of ON [19]. Some limitations of our study need to be mentioned. The cross-sectional design does not allow causal 
inference. The anthropometric measures (height and weight) used to calculate BMI were self-reported. Self-reported BMI score and associated BMI categories tend to be underestimated, with participants with obesity in particular being most likely to be misclassified [60]. Information bias is possible because of difficulties understanding some questions or not answering the questions in a transparent/honest way. The lack of measurement of past or current eating disorders in our sample could impact on our results. A selection bias is present because of the snowball technique followed to collect our sample and because of the refusal rate; therefore, the results obtained might not be generalizable to the whole population. Not all factors associated with $\mathrm{ON}$ were taken into account in this research, predisposing us to a residual confounding bias.

\section{What is already known about the subject?}

A unique study [19] suggested that subjects with orthorexic tendencies might have difficulties in the identification and regulation of their emotions, which is similar to what is already known about other eating disorders.

\section{What does this study add?}

Considering that orthorexia is a newly emerging eating disorder that has not yet been included as a legitimate pathology, our findings provide a pathway for further investigations regarding ON, both in Lebanon and worldwide. Further, the center of our study, ON and emotional difficulties, is novel in Lebanon, a collectivist society, and adds to the scare available research locally and internationally.

\section{Conclusion}

Studying non-clinical populations allowed us to investigate the occurrence of several symptoms without complications of an established illness [59]. Exploring alexithymia and emotion dysregulation were required to fully understand possible emotional processing deficits in individuals with ON tendencies (19). The present research suggests that people with high ON tendencies have difficulties identifying and regulating their emotions as well as difficulties describing emotions, similarly to other eating disorders. In contrast, alexithymia was not found to be a significant predictor of ON. Higher levels of emotion dysregulation was a significant predictor of ON. This may indicate that difficulties identifying, describing and regulating one's own emotions, may be a risk factor for $\mathrm{ON}$.

Acknowledgements The authors would like to thank all the participants who helped us during this project. AB-M acknowledges the financial support from the "Excellence Initiative-Research University" program for years 2020-2026 for University of Wroclaw.

Author contributions SO and SH designed the study; SO, SH and ABM drafted the manuscript; $\mathrm{SH}$ carried out the analysis; $\mathrm{SH}$ and ABM interpreted the results; MA was responsible for the data collection; all authors reviewed the final manuscript and gave their consent.

Funding None.

Availability of data and materials The authors do not have the right to share any data information as per their institutions policies.

\section{Compliance with ethical standards}

Conflict of interest The authors have no conflicts of interest to report.

Ethical approval The Psychiatric Hospital of the Cross Ethics and Research Committee approved the study protocol (HPC-036-2020).

Consent to participate The purpose and requirements of the study were explained to each participant, and filling the form and submitting it online consented that the person approved to participate in the study.

\section{References}

1. Bazzano LA (2006) The high cost of not consuming fruits and vegetables. J Am Diet Assoc 106:1364-1368. https://doi. org/10.1016/j.jada.2006.06.021

2. Bratman S, Knight D (1997) Health food junkie. Yoga J 136:42-50

3. Brytek-Matera A (2012) Orthorexia nervosa — an eating disorder, obsessive-compulsive disorder or disturbed eating habit? Arch Psychiatry Psychother 14:55-60

4. Oberle CD, Samaghabadi RO, Hughes EM (2017) Orthorexia nervosa: Assessment and correlates with gender, BMI, and personality. Appetite 108:303-310. https://doi.org/10.1016/j.appet .2016.10.021

5. Fidan T, Ertekin V, Isikay S, Kirpinar I (2010) Prevalence of orthorexia among medical students in Erzurum, Turkey. Compr Psychiatry 51:49-54. https://doi.org/10.1016/j.compp sych.2009.03.001

6. American Psychiatric Association (2013) Diagnostic and statistical manual of mental disorders, 5th edn. American Psychiatric Association, Arlington

7. Varga M, Thege BK, Dukay-Szabo S, Tury F, van Furth EF (2014) When eating healthy is not healthy: orthorexia nervosa and its measurement with the ORTO-15 in Hungary. BMC Psychiatry 14:59. https://doi.org/10.1186/1471-244X-14-59

8. Bauer SM, Fuste A, Andres A, Saldana C (2019) The Barcelona Orthorexia Scale (BOS): development process using the Delphi method. Eat Weight Disord 24:247-255. https://doi.org/10.1007/ s40519-018-0556-4

9. Donini LM, Marsili D, Graziani MP, Imbriale M, Cannella C (2004) Orthorexia nervosa: a preliminary study with a proposal for diagnosis and an attempt to measure the dimension of the phenomenon. Eat Weight Disord 9:151-157. https://doi.org/10.1007/ BF03325060

10. Missbach B, Hinterbuchinger B, Dreiseitl V, Zellhofer S, Kurz C, Konig J (2015) When eating right, is measured wrong! A validation and critical examination of the ORTO-15 questionnaire in 
German. PLoS ONE 10:e0135772. https://doi.org/10.1371/journ al.pone. 0135772

11. Rogoza R, Donini LM (2020) Introducing ORTO-R: a revision of ORTO-15: Based on the re-assessment of original data. Eat Weight Disord. https://doi.org/10.1007/s40519-020-00924-5

12. Fairburn CG, Cooper Z, Shafran R (2003) Cognitive behaviour therapy for eating disorders: a "transdiagnostic" theory and treatment. Behav Res Ther 41:509-528. https://doi.org/10.1016/s0005 -7967(02)00088-8

13. Cooper MJ (2005) Cognitive theory in anorexia nervosa and bulimia nervosa: progress, development and future directions. ClinPsychol Rev 25:511-531. https://doi.org/10.1016/j. cpr.2005.01.003

14. Lavender JM, Wonderlich SA, Engel SG, Gordon KH, Kaye WH, Mitchell JE (2015) Dimensions of emotion dysregulation in anorexia nervosa and bulimia nervosa: a conceptual review of the empirical literature. ClinPsychol Rev 40:111-122. https://doi. org/10.1016/j.cpr.2015.05.010

15. Westwood H, Kerr-Gaffney J, Stahl D, Tchanturia K (2017) Alexithymia in eating disorders: systematic review and meta-analyses of studies using the Toronto Alexithymia Scale. J Psychosom Res 99:66-81. https://doi.org/10.1016/j.jpsychores.2017.06.007

16. Gratz KL, Roemer L (2004) Multidimensional assessment of emotion regulation and dysregulation: Development, factor structure, and initial validation of the difficulties in emotion regulation scale. J PsychopatholBehav Assess 26:41-54. https://doi.org/10.1023/ B:JOBA.0000007455.08539.94

17. Brockmeyer T, Skunde M, Wu M, Bresslein E, Rudofsky G, Herzog W, Friederich HC (2014) Difficulties in emotion regulation across the spectrum of eating disorders. Compr Psychiatry 55:565-571. https://doi.org/10.1016/j.comppsych.2013.12.001

18. Svaldi J, Griepenstroh J, Tuschen-Caffier B, Ehring T (2012) Emotion regulation deficits in eating disorders: a marker of eating pathology or general psychopathology? Psychiatry Res 197:103111. https://doi.org/10.1016/j.psychres.2011.11.009

19. Vuillier L, Robertson S, Greville-Harris M (2020) Orthorexic tendencies are linked with difficulties with emotion identification and regulation. J Eat Disord 8:15. https://doi.org/10.1186/s4033 7-020-00291-7

20. Sifneos PE (1973) The prevalence of "alexithymic" characteristics in psychosomatic patients. PsychotherPsychosom 22:255-262. https://doi.org/10.1159/000286529

21. Taylor GJ, Bagby RM, Parker JD (1999) Disorders of affect regulation: alexithymia in medical and psychiatric illness. Cambridge University Press, Cambridge

22. Nowakowski ME, McFarlane T, Cassin S (2013) Alexithymia and eating disorders: a critical review of the literature. J Eat Disord 1:21. https://doi.org/10.1186/2050-2974-1-21

23. Strahler J, Stark R (2019) Orthorexia nervosa: VerhaltensauffälligkeitoderneueStörungskategorie? Suchttherapie 20:24-34

24. Keller M, Konradsen H (2013) Orthorexia in young fitness participants. KliniskSygepleje 27:63-71

25. Strahler J (2019) Sex differences in orthorexic eating behaviors: a systematic review and meta-analytical integration. Nutrition 67-68:110534. https://doi.org/10.1016/j.nut.2019.06.015

26. Valera JH, Ruiz PA, Valdespino BR, Visioli F (2014) Prevalence of orthorexia nervosa among ashtanga yoga practitioners: a pilot study. Eat Weight Disord Stud AnorexBulimObes 19:469-472. https://doi.org/10.1007/s40519-014-0131-6

27. Dittfeld A, Gwizdek K, Jagielski P, Brzek J, Ziora K (2017) A Study on the relationship between orthorexia and vegetarianism using the BOT (Bratman Test for Orthorexia). Psychiatr Pol 51:1133-1144. https://doi.org/10.12740/PP/75739

28. Dell'Osso L, Abelli M, Carpita B, Massimetti G, Pini S, Rivetti L, Gorrasi F, Tognetti R, Ricca V, Carmassi C (2016) Orthorexia nervosa in a sample of Italian university population. RivPsichiatr 51:190-196. https://doi.org/10.1708/2476.25888

29. McComb SE, Mills JS (2019) Orthorexia nervosa: a review of psychosocial risk factors. Appetite 140:50-75. https://doi. org/10.1016/j.appet.2019.05.005

30. Eriksson L, Baigi A, Marklund B, Lindgren EC (2008) Social physique anxiety and sociocultural attitudes toward appearance impact on orthorexia test in fitness participants. Scand J Med Sci Sports 18:389-394. https://doi.org/10.1111/j.1600-0838.2007.00723.x

31. Asil E, Surucuoglu MS (2015) Orthorexia Nervosa in Turkish Dietitians. Ecol Food Nutr 54:303-313. https://doi.org/10.1080/03670 244.2014.987920

32. Obeid S, Akel M, Haddad C, Fares K, Sacre H, Salameh P, Hallit S (2019) Factors associated with alexithymia among the Lebanese population: results of a cross-sectional study. BMC Psychol 7:80. https://doi.org/10.1186/s40359-019-0353-5

33. Haddad C, Obeid S, Akel M et al (2019) Correlates of orthorexia nervosa among a representative sample of the Lebanese population. Eat Weight Disord 24:481-493. https://doi.org/10.1007/ s40519-018-0631-x

34. Weary-Smith KA (2007) Validation of the Physical Activity Index (PAI) as a measure of total activity load and total kilocalorie expenditure during submaximal treadmill walking. University of Pittsburgh, Pittsburgh

35. Donini LM, Marsili D, Graziani MP, Imbriale M, Cannella C (2005) Orthorexia nervosa: validation of a diagnosis questionnaire. Eat Weight Disord 10:e28-32. https://doi.org/10.1007/ BF03327537

36. Haddad C, Hallit R, Akel M, Honein K, Akiki M, Kheir N, Obeid S, Hallit S (2020) Validation of the Arabic version of the ORTO15 questionnaire in a sample of the Lebanese population. Eat Weight Disord 25:951-960. https://doi.org/10.1007/s40519-01900710-y

37. Brytek-Matera A, Obeid S, Hallit S (2020) Orthorexia nervosa and disordered eating attitudes among Polish and Lebanese adults. Assessing psychometric proprieties of the ORTO-R in a population-based sample (in review)

38. Preece D, Becerra R, Robinson K, Dandy J (2018) Assessing alexithymia: psychometric properties and factorial invariance of the 20-Item Toronto alexithymia scale in nonclinical and psychiatric samples. J PsychopatholBehav Assess 40:276-287. https://doi. org/10.1007/s10862-017-9634-6

39. Bjureberg J, Ljotsson B, Tull MT, Hedman E, Sahlin H, Lundh LG, Bjarehed J, DiLillo D, Messman-Moore T, Gumpert CH, Gratz KL (2016) Development and validation of a brief version of the difficulties in Emotion Regulation Scale: The DERS-16. J PsychopatholBehav Assess 38:284-296

40. Hallion LS, Steinman SA, Tolin DF, Diefenbach GJ (2018) Psychometric properties of the difficulties in Emotion Regulation Scale (DERS) and its short forms in adults with emotional disorders. Front Psychol 9:539. https://doi.org/10.1007/s1086 2-015-9514-X

41. Haddad C, Khoury C, Salameh P, Sacre H, Hallit R, Kheir N, Obeid S, Hallit S (2020) Validation of the Arabic version of the Eating Attitude Test in Lebanon: a population study. Public Health Nutr. https://doi.org/10.1017/s1368980020002955

42. Garner DM, Olmsted MP, Bohr Y, Garfinkel PE (1982) The eating attitudes test: psychometric features and clinical correlates. Psychol Med 12:871-878. https://doi.org/10.1017/s003329170 0049163

43. Vandekerckhove J, Matzke D, Wagenmakers E-J (2015) Model comparison and the principle of parsimony. Oxford handbook of computational and mathematical psychology. Oxford University Press, Oxford, pp 300-319 
44. Shank LM, Tanofsky-Kraff M, Kelly NR, Jaramillo M, Rubin SG, Altman DR, Byrne ME, LeMay-Russell S, Schvey NA, Broadney MM, Brady SM, Yang SB, Courville AB, Ramirez S, Crist AC, Yanovski SZ, Yanovski JA (2019) The association between alexithymia and eating behavior in children and adolescents. Appetite 142:104381. https://doi.org/10.1016/j.appet.2019.104381

45. Nevin SM, Vartanian LR (2017) The stigma of clean dieting and orthorexia nervosa. J Eat Disord 5:37. https://doi.org/10.1186/ s40337-017-0168-9

46. Koven NS, Abry AW (2015) The clinical basis of orthorexia nervosa: emerging perspectives. Neuropsychiatr Dis Treat 11:385394. https://doi.org/10.2147/NDT.S61665

47. Brewer R, Cook R, Cardi V, Treasure J, Bird G (2015) Emotion recognition deficits in eating disorders are explained by cooccurring alexithymia. R Soc Open Sci 2:140382. https://doi. org/10.1098/rsos.140382

48. Aksoydan E, Camci N (2009) Prevalence of orthorexia nervosa among Turkish performance artists. Eat Weight Disord 14:33-37. https://doi.org/10.1007/BF03327792

49. Kiss-Leizer M, Toth-Kiraly I, Rigo A (2019) How the obsession to eat healthy food meets with the willingness to do sports: the motivational background of orthorexia nervosa. Eat Weight Disord 24:465-472. https://doi.org/10.1007/s40519-019-00642-7

50. Malmborg J, Bremander A, Olsson MC, Bergman S (2017) Health status, physical activity, and orthorexia nervosa: a comparison between exercise science students and business students. Appetite 109:137-143. https://doi.org/10.1016/j.appet.2016.11.028

51. Oberle CD, Watkins RS, Burkot AJ (2018) Orthorexic eating behaviors related to exercise addiction and internal motivations in a sample of university students. Eat Weight Disord 23:67-74. https://doi.org/10.1007/s40519-017-0470-1

52. Rudolph S (2018) The connection between exercise addiction and orthorexia nervosa in German fitness sports. Eat Weight Disord 23:581-586. https://doi.org/10.1007/s40519-017-0437-2

53. Farchakh Y, Hallit S, Soufia M (2019) Association between orthorexia nervosa, eating attitudes and anxiety among medical students in Lebanese universities: results of a cross-sectional study.
Eat Weight Disord 24:683-691. https://doi.org/10.1007/s4051 9-019-00724-6

54. Sanlier N, Yassibas E, Bilici S, Sahin G, Celik B (2016) Does the rise in eating disorders lead to increasing risk of orthorexia nervosa? Correlations with gender, education, and body mass index. Ecol Food Nutr 55:266-278. https://doi.org/10.1080/03670 244.2016.1150276

55. Roncero M, Barrada JR, Perpina C (2017) Measuring orthorexia nervosa: psychometric limitations of the ORTO-15. Span J Psychol 20:E41. https://doi.org/10.1017/sjp.2017.36

56. Grammatikopoulou MG, Gkiouras K, Markaki A, Theodoridis X, Tsakiri V, Mavridis P, Dardavessis T, Chourdakis M (2018) Food addiction, orthorexia, and food-related stress among dietetics students. Eat Weight Disord 23:459-467. https://doi.org/10.1007/ s40519-018-0514-1

57. Zickgraf HF, Ellis JM, Essayli JH (2019) Disentangling orthorexia nervosa from healthy eating and other eating disorder symptoms: relationships with clinical impairment, comorbidity, and self-reported food choices. Appetite 134:40-49. https://doi. org/10.1016/j.appet.2018.12.006

58. Brytek-Matera A, Donini LM, Krupa M, Poggiogalle E, Hay P (2015) Orthorexia nervosa and self-attitudinal aspects of body image in female and male university students. J Eat Disord 3:2. https://doi.org/10.1186/s40337-015-0038-2

59. Yakin E, Raynal P, Chabrol H (2020) Distinguishingorthorexicbehaviors from eating disordered and obsessive-compulsive behaviors: a typological study. Eat Weight Disord. https://doi. org/10.1007/s40519-020-01037-9

60. Gosse M (2014) How accurate is self-reported BMI? Nutr Bull 39:105-114. https://doi.org/10.1111/nbu.12075

Publisher's Note Springer Nature remains neutral with regard to jurisdictional claims in published maps and institutional affiliations. 